\title{
A retrospective study on neonatal mortality over 6 years in a rural teaching hospital
}

\author{
Subhash Shankar Poyekar ${ }^{1}$ Deepali Abhijit Ambike ${ }^{2}$ Rajeshwari Kalyanaraman ${ }^{3}$, \\ Ravikant Kumar Bhogshetti ${ }^{3}$ \\ From ${ }^{1}$ Associate Professor, Department of Paediatrics, Rural Medical College, Ahmednagar, ${ }^{2}$ Professor and Head, Department of Paediatrics, \\ Postgraduate Institute Yashwantrao Chavan Memorial Hospital, ${ }^{3}$ Intern, Department of Paediatrics, Maharashtra Institute of Medical Education and \\ Research Medical College, Pune, Maharashtra, India
}

\begin{abstract}
Background: India has a high neonatal mortality rate (NMR) of 31/1000 live births that of rural being 34 while urban is 17. Approximately two-thirds of the newborn deaths usually occur in the $1^{\text {st }}$ week of life. Objective: This study was conducted to identify primary causes of neonatal deaths and to analyze the trend over 6 years. Methods: This was a record-based observational study of all the neonatal deaths born in a tertiary hospital of West India over 6 years (January 2012-December 2017). All the admitted babies to neonatal intensive care unit (NICU) were included in the study. Details of each neonatal death were analyzed. Results: Out of the total 6561 births, there were 146 neonatal deaths during the study period. The maximum NMR was 36.2/1000 live births in the year 2012. There was decreasing trend of death rate over 5 years with marginal increase in the year 2017 (16.6/1000 live births), attributed to congenital malformations and perinatal asphyxia. Among them, $87 \%$ were low birth weight, $61 \%$ were male, and $71.9 \%$ were preterm. The causes of neonatal death were septicemia, extreme prematurity, respiratory distress syndrome, birth asphyxia, meconium aspiration, and congenital anomalies. Conclusions: In the present study, NMR showed decreasing trend over 6 years. Prevention of premature delivery, proper management of very low birth weight babies, and early detection and appropriate management of septicemia/perinatal hypoxia have become important interventional strategies in reducing neonatal deaths.
\end{abstract}

Key words: Neonatal death, Neonatal mortality rate, Prematurity, Respiratory distress syndrome

$\mathrm{E}$ very year, 4 million deaths are reported in the neonatal period (first 4 weeks of life), with India contributing to one-fourth of the total mortality burden. The World Health Organization stated that around 5.9 million children died under 5 years of age in 2015 (16,000 deaths/day) [1]. According to the sample registration system statistical report 2016, the current neonatal mortality rate (NMR) in India is 24, ranging from 14 in urban to 27 in the rural areas [2].

Neonatal deaths are the highest contributors to infant and under-5 mortality rate. Approximately $75 \%$ of the neonatal deaths occur in the $1^{\text {st }}$ week of life, with nearly $25 \%$ of them occurring within the first $24 \mathrm{~h}$ of life. Deaths occurring in neonatal intensive care units (NICUs) have a major influence on infant mortality. Understanding the causes of death in NICUs and the preventable factors associated with death has the potential to decrease infant mortality [3]. During recent years, there is decreasing trend

\section{Access this article online}

Received - 10 August 2020

Initial Review - 25 August 2020

Accepted - 26 September 2020

DOI: $10.32677 / \mathrm{IJCH} .2020 . v 07.110 .002$ in infant mortality (deaths in infants 1-12 months of age), but practically no change in NMR is evident. Preterm and low birth weight are at increased risk of morbidity and mortality [4].

NMR is one of the important and sensitive indicators of the availability, utilization, and effectiveness of the health services in the community. NMR reflects the quality of service available. The causes of neonatal deaths vary in different countries with the availability and quality of health care; therefore, understanding neonatal mortality in relation to these factors is crucial. Many costeffective interventions can avert neonatal mortality. Hence, this study was conducted to find out the neonatal mortality pattern and to identify primary causes of neonatal deaths in NICU of the rural hospital attached to the medical college.

\section{MATERIALS AND METHODS}

The present retrospective observational study was conducted in the NICU of a rural tertiary hospital of West India between January 1, 2012, and December 31, 2017. The inclusion criteria

Correspondence to: Dr. Deepali Abhijit Ambike, Department of Pediatrics, Postgraduate Institute Yashwantrao Chavan Memorial Hospital, Pimpri, Pune 411 018, Maharashtra, India. E-mail: ambikedeepa@gmail.com

(C) 2020 The Author(s). This open access article is distributed under a Creative Commons Attribution (CC-BY) 4.0 license. 
were all newborns requiring neonatal care, who were born from January 1, 2012, to December 31, 2017, in the hospital. There were no exclusion criteria.

As it was a retrospective record-based study over a period of 6 years, hence all the newborns admitted to NICU during that period were included for the study. Indoor admission papers of mothers and neonates were studied in detail. The necessary information such as labor notes, perinatal events, neonatal clinical examination, and treatment with clinical progress was collected. The birth statistics was obtained from the birth register in the labor ward. Since this was a retrospective study, the requirement of informed consent was waived.

Ethical approval was obtained from the Institutional Ethics Committee. The analysis of the data was done by descriptive statistics with percentages and proportions. Comparisons were done by "t-test" or Chi-square test and significant $\mathrm{p}<0.05$.

\section{RESULTS}

There were a total of 6561 live births with 146 neonatal deaths during the study period. Year-wise total numbers of live births and neonatal deaths from 2012 to 2017 are shown in Figure 1. The $\mathrm{X}$-axis shows the total number of live births and neonatal deaths and the Y-axis shows the years in ascending order. From 2012 to 2017 , there was a reduction in neonatal deaths.

Sepsis was main cause of death during 2012 which has shown decline in subsequent years except in the year 2015. Death due to extreme prematurity showed an increasing trend from 2012 to 2016 , but there was better survival in extremely premature/ low birth weight babies in 2017. In the year 2017, death among premature babies was relatively less when compared to deaths in the previous years. Death among male neonates was more during the study period except in the year 2015 .

We analyzed the deaths according to the birth weight, gender, gestational age, and appropriateness for age (Table 1). The smaller the babies at birth had higher risk of death. During the period of analysis, the total number of male neonatal deaths outnumbered the female deaths.

Sepsis was main cause of mortality (Table 2), which was followed by extreme prematurity, hyaline membrane disease, meconium aspiration syndrome, perinatal asphyxia, and congenital anomalies.

Maximum deaths occurred during early neonatal period and more than one-third died within the first $24 \mathrm{~h}$ of birth (Table 3 ).

\section{DISCUSSION}

The NMR for the year 2017 was 16.6/1000 live births. Malik et al. reported it as $26.66 \%$ in Bhopal [5], while in Gandhinagar $9.42 \%$ by Modi et al. [6], in Mandya $7.16 \%$ by Sridhar et al. [7], $13.77 \%$ in Guwahati by Saharia et al. [8], and $23.40 \%$ in Patna by Ranjan and Singh [9]. Death rate in this study was much lower than that observed in a study done from a tribal area of Maharashtra [10].

Irrespective of the gestational age, male neonates have higher global biological risk of death than female neonates [11]. The same pattern was observed in our study cohort as the majority $(61 \%)$ of neonates who died were male. Similar observation has been reported in the previous studies [12].

The risk of death is greatest on the $1^{\text {st }}$ day of life for a liveborn neonate. Globally, the proportion of deaths during the $1^{\text {st }}$ day and week of life is consistent across the different regions and economical settings $[11,12]$. In our study, the percentage of early neonatal deaths was $59.6 \%$ with more than one-third of them occurring during the first $24 \mathrm{~h}$.

Gestational age had inverse relation with early neonatal mortality in the present study. Preterm babies contributed 78.2\% of early neonatal deaths. Results in the present study are in concurrence with the study by Pradeep et al. who observed 78\% of early neonatal deaths in preterm babies [13].

There was an inverse relationship between birth weight and early neonatal deaths. Preterm small for gestational age babies contributed more to early neonatal deaths [14]. Prematurity and birth weight are important factors in determining survival of neonates in NICU, as in the present study, preterm neonates had roughly twice the risk of mortality compared with term neonates. In this study, assisted and operative deliveries were risk factors for neonatal death. This was a comparable result with a study conducted by Yirgu et al. revealed that spontaneous vaginal

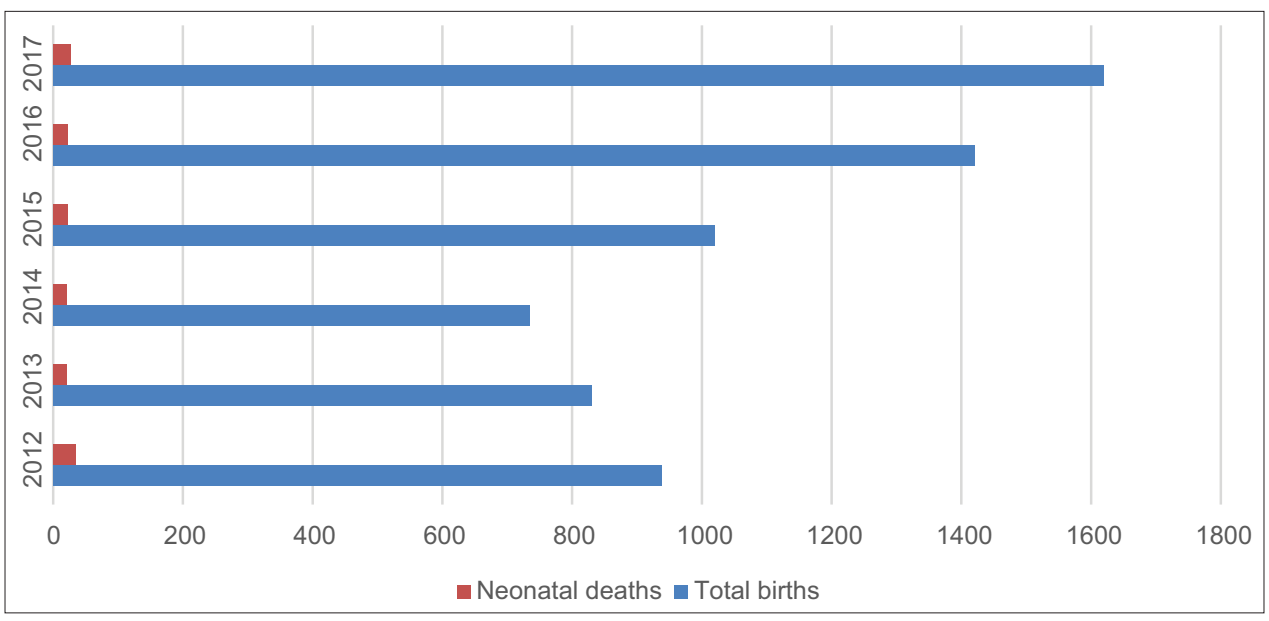

Figure 1: Total numbers of live births and neonatal deaths from year 2012 to 2017 
Table 1: Clinicodemographic characteristics of the study subjects

\begin{tabular}{|c|c|c|c|c|c|}
\hline Variable & $\mathbf{n}$ & $\%$ & Variable & n & $\%$ \\
\hline \multicolumn{2}{|c|}{ Birth weight (Kg) } & \multicolumn{3}{|c|}{ Gestational age (weeks) } & \\
\hline$<1$ & 37 & 25.3 & $<28$ & 22 & 15.0 \\
\hline $1-1.5$ & 47 & 32.2 & $28-34$ & 41 & 28.1 \\
\hline $1.5-2.5$ & 43 & 29.5 & $34-37$ & 42 & 28.8 \\
\hline$>2.5$ & 19 & 13.0 & $>37$ & 41 & 28.1 \\
\hline Gender & \multicolumn{5}{|c|}{ Weight for gestational age } \\
\hline Male & 89 & 61 & AGA & 94 & 64.4 \\
\hline Female & 57 & 39 & SGA & 52 & 35.6 \\
\hline
\end{tabular}

AGA: Appropriate for gestational age; SGA: Small for gestational age

Table 2: Mortality pattern among neonates admitted in NICU

\begin{tabular}{lccccc}
\hline Causes of death & $\mathbf{n}(\%)$ & Preterm & Term & AGA & SGA \\
\hline Sepsis & $39(26.7)$ & 30 & 9 & 20 & 19 \\
Extreme prematurity & $31(21.2)$ & 31 & 0 & 25 & 6 \\
HMD & $29(19.9)$ & 29 & 0 & 19 & 10 \\
MAS & $20(13.7)$ & 4 & 16 & 12 & 8 \\
Perinatal asphyxia & $17(11.6)$ & 6 & 11 & 13 & 4 \\
Congenital anomalies & $10(06.9)$ & 5 & 5 & 5 & 5 \\
Total & 146 & 105 & 41 & 94 & 52 \\
\hline
\end{tabular}

AGA: Appropriate for gestational age, SGA: Small for gestational age, HMD: Hyaline membrane disease, MAS: Meconium aspiration syndrome. NICU: Neonatal intensive care unit

Table 3: Frequency distribution of the study subjects according to LOS and mode of delivery

\begin{tabular}{lcc}
\hline LOS (days) & $\mathbf{n}$ & $\mathbf{\%}$ \\
\hline$<1$ & 31 & 21.23 \\
$1-3$ & 56 & 38.36 \\
$4-7$ & 32 & 21.92 \\
$>7$ & 27 & 18.49 \\
Mode of delivery & & \\
$\quad$ Vaginal & 98 & 67.12 \\
Cesarean & 48 & 32.88 \\
\hline
\end{tabular}

LOS: Length of stay

delivery is a protective factor for neonatal death than cesarean delivery [15].

Identification of causes of deaths is a guide to implement strategies to minimize the preventable neonatal deaths and to reduce the overall infant mortality. The most common cause of neonatal death in our study group was septicemia (26.7\%) followed by extreme prematurity (21.2\%). In 2012, globally, 36\% of neonatal deaths were due to prematurity, $23 \%$ were due to birth asphyxia, and 23\% were due to sepsis [13]. However, there are variations between countries. Pandya et al. have reported that sepsis contributed maximally to the mortality [16]. Similarly, the study report by the Indian Council of Medical Research also states sepsis to be the major cause of neonatal death [17]. The other leading causes of neonatal deaths in our study were respiratory distress syndrome, meconium aspiration, birth asphyxia, and congenital malformations. The variation was noted over the years. The most common congenital malformation was congenital heart disease.
The proportion of neonatal mortality in our institution has decreased from 2012 to 2017. The reasons for the improvement were multifactorial. In our setting, the use of advanced ventilation strategies, strict infection control measures, improvement in knowledge, skills, and experience in managing preterm neonates, high numbers of resuscitation workshops held over the past years for medical and nursing staff, and compulsory resuscitation workshops for pre-interns could have contributed to this success. Thus, to accomplish the sustainable development goal of reducing the low birth weight deliveries by $30 \%$ by 2025 , strengthening and implementation of good obstetric care is of paramount importance.

Considering the results of the previous years, strengthening the obstetric, perinatal, and neonatal care, minimizing perinatal and nosocomial infections, and strengthening the knowledge and practical skills of neonatal resuscitation in midwives, nurses, and medical officers are of paramount importance to reduce prematurity, asphyxia, and sepsis-related deaths. Considering the significant contribution of congenital abnormalities toward neonatal deaths, routine antenatal ultrasound with referral for anomaly scan when indicated should be incorporated into national obstetric guidelines. Addressing preterm birth is the most vital aspect to accelerate the progress and to achieve the national, targets, as many deaths are due to direct complications of extreme prematurity.

The findings of the current study should be deduced keeping in view the subsequent limitations. As it was a hospital-based study and as most of the patients had a low socioeconomic status, the results of this study may not give representativeness of the true disease burden which is prevalent in the community. Maternal details were not studied in the present study. Authors were unable to diagnose inborn errors of metabolism and establish echo confirmed diagnosis of congenital heart diseases due to lack of diagnostic facilities.

\section{CONCLUSIONS}

Neonatal death proportions have shown a downward trend during the study period, with marginal increase in 2017, which may be because of congenital malformations and perinatal asphyxia. Prevention of premature delivery, proper management of very low birth weight babies, and early detection and appropriate management of septicemia/perinatal hypoxia have become important interventional strategies in reducing neonatal deaths.

\section{REFERENCES}

1. Bryce J, Boschi-Pinto C, Shibuya K, Black RE. WHO estimates of the causes of death in children. Lancet 2005;365:1147-52.

2. Registrar General and Census Commissioner India. Sample Registration System Bulletin 2016. Estimates of Mortality Indicators (SRS 2011-13); 2014. Available from: http://www.censusindia.gov.in/vital_statistics/SRS reports_2013.html. [Last accessed on 2020 Aug 08].

3. Jacob J, Kamitsuka M, Clark RH, Kelleher AS, Spitzer AR. Etiologies of NICU deaths. Pediatrics 2015;135:e59-65.

4. Lawn JE, Cousens S, Zupan J, Lancet Neonatal Survival Steering Team. 4 
million neonatal deaths: When? Where? Why? Lancet 2005;365:891-900.

5. Malik S, Gohiya P, Khan IA. Morbidity profile and mortality of neonates admitted in neonatal intensive care unit of a central india teaching institute: A prospective observational study. J Clin Neonatol 2016;2:168-73.

6. Modi R, Modi B, Patel JK, Margaret P. Study of the morbidity and the mortality pattern in the neonatal intensive care unit at a tertiary care teaching Hospital in Gandhinagar District, Gujarat, India. J Res Med Dent Sci 2015;3:208-12.

7. Sridhar PV, Thammanna PS, Sandeep M. Morbidity pattern and hospital outcome of neonates admitted in a tertiary care teaching hospital, Mandya. Int J Sci Stud 2015;3:126-9.

8. Saharia N, Deka A, Vivekananda M. Mortality and morbidity pattern of neonatal ICU of Gauhati medical college and hospital. IOSR J Dent Med Sci 2016;15:73-5.

9. Ranjan A, Singh A. Pattern of morbidity and mortality of neonates admitted in tertiary level neonatal intensive care unit in Nalanda medical college and hospital, Patna, Bihar, India. Int J Contemp Pediatr 2016;3:854-7.

10. Mehkarkar N, Sonawane VB. A study of early neonatal mortality in a tertiary hospital of Maharashtra, India. Int J Contemp Pediatr 2018;5:1869-74.

11. Lawn J, Blencowe H, Oza S, You D, Lee A, Waiswa P, et al. Every newborn: Progress, priorities, and potential beyond survival. Lancet 2014;384:189-205.

12. Weerasekera M, Amarasekara S, Siriwardhane HV. An analysis of neonatal mortality in a tertiary care hospital over a decade-2008 to 2017. Sri Lanka J Child Health 2019;48:326-33.
13. Pradeep M, Rajam L, Sudevan P. Perinatal mortality: A hospital based study. Indian Pediatr 1995;32:1091-4.

14. Adikane H, Surwase K, Pawar V, Chaudhari K. A prospective observational study of morbidity and mortality profile of neonates admitted in neonatal intensive care unit of secondary care centre in central Maharashtra, India. Int J Contemp Pediatr 2018;5:1403-8.

15. Yirgu R, Molla M, Sibley L, Gebremariam A. Perinatal mortality magnitude, determinants and causes in West Gojam: Population-based nested casecontrol study. PLoS One 2016;11:e0159390.

16. Pandya NK, Mehta KG. Study of morbidity and mortality profile in special care newborn unit at tertiary care teaching institute in Vadodara, Gujarat, India. Int J Contemp Pediatr 2018;5:1763-6.

17. ICMR Young Infant Study Group. Age profile of neonatal deaths. Indian Pediatr 2008;45:991-4.

Funding: None; Conflicts of Interest: None Stated.

How to cite this article: Poyekar SS, Ambike DA, Kalyanaraman R, Bhogshetti RK. A retrospective study on neonatal mortality over 6 years in a rural teaching hospital. Indian J Child Health. 2020; 7(10):404-407. 